\title{
Seizures in Children in the Lagoon Mother and Child University Hospital Center (CHUMEL) of Cotonou: Community Practices and Risk Factors for Death in Benin
}

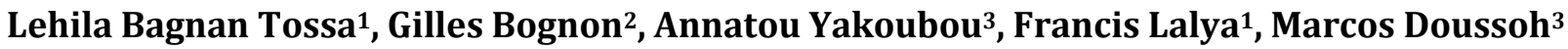 \\ ${ }^{1}$ University Clinic of Pediatrics and Medical Genetics of the National Hospital and University Center Hubert K. MAGA of \\ Cotonou, Cotonou, Benin \\ ${ }^{2}$ Pediatric of the University and Departemental Hospital Center of Ouémè-Plateau, Porto-Novo, Benin \\ ${ }^{3}$ Pediatric Ward of the Lagoon Mother and Child University Hospital Center of Cotonou, Cotonou, Benin \\ Email: tossabagn@yahoo.fr
}

How to cite this paper: Tossa, L.B., Bognon, G., Yakoubou, A., Lalya, F. and Doussoh, M. (2019) Seizures in Children in the Lagoon Mother and Child University Hospital Center (CHUMEL) of Cotonou: Community Practices and Risk Factors for Death in Benin. Open Journal of Pediatrics, 9, 273-280.

https://doi.org/10.4236/ojped.2019.94025

Received: July 8, 2019

Accepted: October 27, 2019

Published: October 30, 2019

Copyright () 2019 by author(s) and Scientific Research Publishing Inc. This work is licensed under the Creative Commons Attribution International License (CC BY 4.0).

http://creativecommons.org/licenses/by/4.0/ (c) (i) Open Access

\begin{abstract}
Introduction: The experience of convulsions is full of myths in our socio-cultural context. Objectives: To determine the frequency of seizures, to identify community practices in the care of seizures and the death risk factors. Methods: We conducted a prospective, descriptive and analytical study between April and August 2015 in the pediatric ward of the Lagoon Mother and Child University Hospital Center (CHUMEL) of Cotonou. We included children aged from 1 month to 15 years old hospitalized for either febrile or non-febrile convulsions happened at home. Results: A total of 102 cases of convulsion were included, $11.3 \%$ of hospitalizations. These were mostly children under 5 years, 87/102 (85.3\%). Traditional resuscitation procedures were performed on 81 children (79.4\%). They consisted of the forced introduction of objects in the mouth in 46 cases (46.1\%), the oral administration of various products in 39 cases $(38.2 \%)$, the ocular instillation of products in 10 cases $(9.8 \%)$. Nineteen bodily injuries were found. The lethality was $15.8 \%$. The risk factors for death identified were the use of traditional healers and the delay in consultation. Conclusion: The high frequency of seizures, the severity of seizures, the harmful traditional practices performed, and the delay to consultation require to strengthen the education of the population.
\end{abstract}

\section{Keywords}

Seizures, Traditional Resuscitation, Child, Benin 


\section{Introduction}

Seizures are a common reason for consultation and hospitalization in pediatric wards. They constitute a potentially serious pediatric emergency [1] [2]. The problem of convulsions lies neither in their frequency nor in their recognition, both known. It exists rather in the research of the etiology which conditions the therapeutic management. In west Europe, $5 \%$ to $9 \%$ of children experience at least on febrile convulsion within their first 5 years. In Africa, febrile convulsions are the most frequent because of the prevalence of infectious pathology including malaria. The management of convulsions varies from one country to another, considering differences in the environment, medical density and those relating to socio-cultural and economic implications. In our socio-cultural context, seizures look like supernatural causes [3] [4]. The crisis is always described by a symbolism that refers to epilepsy, which in Africa, is a socio-cultural origin of disease, not medical thereby priority use of traditional treatments whose practices are often harmful [5] [6]. According to a study conducted in 2003 in the pediatric department of the Cotonou CNHU, certain harmful community practices have been reported [6]. This study, carried out in the Pediatric Ward of the Lagoon Mother and Child University Hospital Center (CHUMEL), aimed to contribute to the improvement of the management of convulsions, to determine their frequency, and to identify community practices and risk factors for death.

\section{Patients and Methods}

It was a prospective study referred descriptive and analytical conducted from April $1^{\text {st }}$ to $15^{\text {th }}$ of August 2015 in the Pediatric Service of the CHUMEL, a teaching hospital.

Children aged between one month and 15 years admitted to the pediatric emergencies then hospitalized for either febrile or non-febrile seizures which happened at home and whose parents agreed to participate in the study were included. Children with hospital onset of seizures were not included.

The variables studied were:

- Socio-demographic: age, sex, ethnicity, religion, and mother's educational level.

- Clinical: admission mode, seizure's description, bodily injury following traditional resuscitation practices, elapsed time before presenting to the pediatric emergency department.

Care taking before admission: the therapeutic route, the gestures of resuscitation and the cult practices and the evolution.

The collection technique was interview and direct observation. Our sources of data included service records and medical files. The data was collected using a questionnaire analyzed and processed in Excel and using the SPSS21 software. The comparison of the proportions was made using the Chi2 and exact Fischer test. $p$ value less than 0.05 was regarded as statistically significant.

The anonymity and confidentiality of the data have been respected. 


\section{Results}

Sociodemographic characteristics of the study population

During the study period, 903 children from 1 month to 15 years were hospitalized, among them 102 children meeting the inclusion criteria were identified, that corresponds to $11.3 \%$ of hospitalizations.

There were 51 boys (50\%) and 51 girls (50\%). The average age was 36 months, extreme ( 2 months and 132 months). Children under 5 years were the most numerous with $87 / 102$ cases $(85.3 \%)$. The children were of Christian parents in 79 cases $(77,5 \%)$, Muslim in 9 cases $(8.8 \%)$ and animist in 14 cases (13.7\%).

The education level of mothers was the primary education level in 45 cases $(44.2 \%)$, secondary in 19 cases $(18.6 \%)$ and higher in 5 cases $(4.9 \%)$. In 33 cases (32.3\%), these were out-of-school mothers.

Clinical features of the study population

- Mode of admission

Seventy-one children (69.6\%) received in the pediatric emergency department were referred from peripheral medical centers. Nineteen children (18.6\%) stayed with a traditional practitioner or in a church, and 12/102 (11.7\%) came directly from home to the pediatric ward of the CHUMEL.

- Description of crisis

The seizures were associated with fever in $98 \%$ of cases. Generalized tonic and tonic-clonic seizures were described in 54/102 (53\%) of patients, focal seizures in $17 / 102(16.7 \%)$ and ocular revulsions in 31/102 (30.3\%).

- Traditional resuscitation gestures

The children had several traditional resuscitation procedures performed by the parents as shown in Table 1.

- Injuries secondary to the traditional resuscitation

Nineteen children (18.6\%) presented damages secondary damage to a traditional resuscitation gesture. Each child had one or more injuries at a time. The most affected body part was the head as shown in Table 2.

\section{- Delay before consultation at CHU-MEL}

The average pediatric emergency consultation time was 48 hours, range (1 hour and 96 hours) as shown in Table 3.

\section{$\checkmark$ Evolution}

The evolution was favorable for 83 children (81.4\%), 16 children (15.7\%) died and two children were released against medical advice.

\section{Relationship: Care pathway and evolution:}

The relationship between care pathways and evolution showed that the risk of death was five times higher for children who went to traditional healers or to church (Table 4).

- Relationship between the consultation period and the evolution of children

At a delay of more than 72 hours, the risk of death was much greater ( $\mathrm{p}=$ 0.001) (Table 5). 


\section{Comments}

The hospital frequency estimated at $11.30 \%$ in this study shows that seizures constitute a major public health problem. Frequencies higher than ours were reported in our country by Alao et al. in 2011 with 16.88\% [7] in Cotonou and by Adédémy in Parakou in 2011 with 14.99\% [8]. The differences in frequency between these studies are related to the study population and design. In our work, the non-inclusion of convulsions that occurred during hospitalization is one of that. Results from African studies are similar to our data with frequencies varying from $7 \%$ to $23 \%$ [3] [4] [5] [7] [9] [10] [11].

Table 1. Distribution of children according to the procedures of resuscitation undergone before admission.

\begin{tabular}{|c|c|c|}
\hline Traditional resuscitation gestures $^{1}$ & Staffs & Percentages (\%) \\
\hline Slaps or pressure on part of the body & 78 & 76.4 \\
\hline Forced introduction of finger or objects in the mouth & 47 & 46.1 \\
\hline Oral administration of various products ${ }^{2}$ & 39 & 38.2 \\
\hline Instillation of various products in the eyes ${ }^{3}$ & 10 & 9.8 \\
\hline Water spraying (cold) to the face and wet wrap & 9 & 8.8 \\
\hline Whole-body application of various products ${ }^{4}$ & 5 & 4.9 \\
\hline Instillation of traditional powder in the nostrils & 1 & 0.09 \\
\hline Application of hot metal on the body & 1 & 0.09 \\
\hline
\end{tabular}

${ }^{1}$ Gestures were isolated or associated; ${ }^{2}$ Oil of cod liver, palm nut, olive $(n=14)$, herbal teas $(n=11)$, honey, sugar, lemon $(n=9)$, holy salt water $(n=5) ;{ }^{3}$ Salt salt water, lemon juice, menthol products; ${ }^{4}$ Cod liver oil, traditional ointment, menthol products, blessed perfume.

Table 2. Distribution of children according to injury secondary to traditional resuscitation.

\begin{tabular}{ccc}
\hline Topographies & lesions & Effective \\
\hline Eye damage & Conjunctivitis & 7 \\
& Periorbital edema & 4 \\
Oral impairment & Edema and wounding of the lips & 9 \\
Attack of the face & Injury of the tongue & 3 \\
Other & Dental avulsion & 5
\end{tabular}

*The topography of the lesions was isolated or associated.

Table 3. Distribution of children according to the time of consultation between the occurrence of the crisis and admission to the CHUMEL.

\begin{tabular}{ccc}
\hline Consultation time & Effective & Percentage \\
\hline Less than $24 \mathrm{~h}$ & 58 & 56.9 \\
$24-72 \mathrm{~h}$ & 37 & 36.3 \\
More than 72 hours & 7 & 6.8 \\
Total & 102 & 100
\end{tabular}


Table 4. P arches of care and evolution of children.

\begin{tabular}{ccccc}
\hline \multicolumn{5}{c}{ Evolution of children } \\
\hline Care paths & Death & Favorable & p & 0R IC 5\% \\
\hline Traditional healers & & & & \\
Yes & 5 & 7 & $0.020^{1}$ & 5.13 [1.39 - 19.0] \\
No & 11 & 79 & & \\
Celestial, Evangelical Church & & & & \\
Yes & 2 & 5 & $0.669^{1}$ & 0.97 [0.09 to 5.25] \\
No & 14 & 81 & & \\
Peripheral center & & & & \\
Yes & 8 & 57 & $0.214^{2}$ & $0.51[0.15$ to 169$]$ \\
No & 8 & 29 & & \\
\hline${ }^{1}=$ exact Fischer test. ${ }^{2}=$ Pearson chi2 test. & & & &
\end{tabular}

Table 5. Relationship between the consultation period and the evolution of children.

\begin{tabular}{ccccc}
\hline \multicolumn{5}{c}{ Evolution of children } \\
Consultation time & Death & Favorable & $\mathrm{p}$ & OR IC 95\% \\
\hline$>72 \mathrm{~h}$ & 5 & 5 & 0.001 & $19.09[2.6 ; 211.6]$ \\
$\leq 72 \mathrm{~h}$ & 11 & 84 & & \\
\hline
\end{tabular}

Seizures are more common in children under 5 years of age in malaria endemic areas, with malaria being the leading cause of morbidity in this age group [7]. In Benin, malaria counts for $80 \%$ of the causes of convulsions in children [7] [8].

Seizures predominate in children of mothers with low education and low socioeconomic status as already reported [7] [8]. The corollary is the practice of so-called traditional resuscitation gestures whose harmful effects were found in this study like injuries, as reported by Jarett, O. et al. in Nigeria [12].

The use of traditional resuscitation practice is a known fact in Benin [6]. These practices have been reported in sub-Saharan Africa, particularly in Côte d'Ivoire, Togo, Mali, Nigeria, Senegal and Malawi [9]-[16], as well as in India [17] [18] [19].

Those practices are linked to the perceived social and cultural dimensions of seizures by the population living in Cotonou and broadly in Benin [6] [20]. The belief that witchcraft and curse could be diseases' origin is more common in Benin than France [5] wherein Moretti had described more rational seizures' management practices at home. Those adequate practices included: putting the child in security lateral position in $36 \%$ of the cases, intra-rectal diazepam ad-ministration (40\%), phone call to a medical emergency unit within $18 \mathrm{mi}$ nutes [3]. It's unanimously reported in the literature that traditional resuscitation practices are due to parents fearing occurrence of the child's death. The absolute objective is then to keep the child alive whatever he cost. This will cause 
the parents inflicting to the child all kind of pain in order to prevent him from "closing his eyes or mouth for good" or losing his sensitiveness.

Oral aggression with objects introduction into the mouth has been described in Nigeria where a rate of $61.2 \%$ was found and in China with a rate of $40 \%$ [13] [16]. Eyes aggression with irritants product instillation has resulted in conjunctivitis, but more severe lesions with sequelae like blindness have been described [6] [12]. The less common practices were burns, found in one child. This rate is much lower than the literature data where it ranged from $1.4 \%$ to $8 \%$ [6] [12]. Oral administration of various products such as herbal mixtures preparations, cod liver oil, palm nut oil, or honey during the crisis or the post-critical coma have been described by other authors both Beninese and foreign [6] [8] [12]. This practice is in line with the many virtues attributed rightly or wrongly to products traditionally used to lower fever, stop seizures or put the child to sleep. In Nigeria, the same practice has been twice as implemented [13]. The most used product was a mixture of cow or human urine with tobacco leaves, onion, basil leaves, lemon juice and salt. This mixture has been described as a poison since 1975 and can cause hypoglycaemia, hypotension, respiratory distress and seizures [21]. This practice therefore entails risks of intoxication. In addition, a risk of inhalation pneumopathy related to this practice has been described [3].

The convulsive child suffers not only from his illness but also from the abuse he is subjected to by ignorance of society. Traditional resuscitation bad practices can thus worse the patients' evolution and prognosis. The solution is firstly, to adequately train the medical and paramedical staff for a correct management of seizures. Secondly families and the general public should be educated for a less dramatic perception of seizures.

The educational facilities are numerous and efficient if used wisely. Also, before considering the seizures from the medico-social angle, it would be necessary to demystify this symptom.

The severity of seizures is explained by high lethality (15.7\%). The factors associated with death were the visit to a traditional healer and the delay in the consultation.

To reduce the lethality of convulsions in our socio-cultural context, we should organize strategies of education for the population through well-codified programs on good practices to adopt with the participation of health professionals, psychologists and sociologists as done in China [22].

\section{Conclusion}

Community practices of traditional resuscitation in the face of seizures are still a reality. They are very physically violent and, and responsible for a still high lethality in children, especially the under 5 years. It is important to educate people by strengthening campaigns during immunization sessions and the use of mass media among others. 


\section{Conflicts of Interest}

The authors declare no conflicts of interest regarding the publication of this paper.

\section{References}

[1] Dulac, O. (2007) Convulsion of the Child. Medico-Surgical Encyclopedia 25-140-G-20.

[2] Bourillon, A. (2011) Pediatrics for the Practitioner. In: Collection for the Practitioner, 5th Edition, 587.

[3] Morreti, R., Julliand, S., Huet, S., Boizeau, P., Maury, I. and Lode, N. (2013) The Parents Take Care of the Convulsions of the Child at Home. Annales françaises de médecine d urgence, 3, 205-211. https://doi.org/10.1007/s13341-013-0316-Z

[4] Ezeala-Adikaibe, B.A., Achor, J.U., Nwabueze, A.C., Agomoh, A.O., Chikani, M., Ekenze, O.S. and Onwuekwe, I.O. (2014) Enugu, South East Nigeria, Knowledge, Attitude and Practice of Epilepsy among Community Residents. Seizure, 23, 882-888. https://doi.org/10.1016/j.seizure.2014.08.003

[5] Nubukpo, P., Prens, P.M., Clement, J.P. and Houinato, D. (2003) Comparison of Socio-Cultural Representations of Epilepsies in Limousin (France), Togo and Benin (Africa). Médecine Tropicale, 63, 143-150.

[6] Lalya, H.F., Almeida, M., Kpatchavi, A., Fiossi-Kpadonou, E., Koumakpai, S. and Ayivi, B. (2007) Sociological Approach to the Management of Convulsions in Children in Cotonou. Médecine d Afrique noire électronique, 54, 396-400.

[7] Alao, M.J., Zoumenou, E., Sagbo, G. and Padonou, C. (2013) Management of Child Seizures in a University Pediatric Ward in Cotonou, Benin. Médecine d Afrique noire électronique, 12, 527-531.

[8] Adedemy, J.D., Agossou, J., Noudamadjo, A., Ouendo, M.A. and Almeida Hounnou, M. (2013) The Feverish Seizures of the Child in a Pediatric Hospital in Parakou (Benin) in 2013. Bulletin de la Société de Pathologie Exotique, 106, 334-359.

[9] Asse, K.V., Pio, K.J., Akkafou, E., Adonis Koffy, L., Yenan, J. and Kouamè, N.M. (2010) Febrile Occasional Seizures of the Child in Abidjan. Africa Biomedical, 5, 22-31.

[10] Douti, N.K., Dassa, S.K., Koffi, S.K., Djadou, K.E., Essizewa, K.E. and Degue, M.D. (2011) Convulsions Simple Hyper Pyretic in Children 6 to 60 Months: Epidemiological and Clinical Aspects. Journal de la Recherche Scientifique de I Université de Lomé, 13, 1-4.

[11] Maiga, Y., Napo, C., Dicko, F., Fofana, T., Traore, B., Sidibé, L.N. and Diakite, A. (2011) Knowledge about Epilepsy and Attitudes of Child Parents in Mali: Community Study. Le Mali medical., 27, 30-33.

[12] Jarrett, O., Fatunde, O., Osinusi, K. and Lagunju, I. (2012) Pre-Hospital Management of Febrile Seizures in Children at the University College Hospital, Ibadan Nigeria. Annals of Ibadan Postgraduate Medicine, 2, 6-10.

[13] Anigilaje, E.A. and Anigilaje, O.O. (2012) Childhood Convulsion: Inquiry about the Concerns and Home Management among Mothers in Tegbesun, Periurban Community in Ilorin, Nigeria. ISRN Pediatrics, 2012, Article ID: 209609. https://doi.org/10.5402/2012/209609

[14] Faye, M., N’Diaye, M., Gueye Diagne, M.C., Sarr Niang, N.T. and Yam, A.A. (2007) Study of Oro-Dental Injuries during Seizures in Senegalese Children with Epilepsy. 
Odonto-Stomatologie Tropicale, 30, 23-30.

[15] Kolahi, A.A. and Tahmooreszadeh, S. (2009) First Febrile Seizures: Inquiry about the Knowledge, Attitude and Concerns of the Patients' Mother. European Journal of Pediatrics, 168, 167-171. https://doi.org/10.1007/s00431-008-0724-z

[16] Huang, M.C., Liu, C.C., Huang, C.C. and Thomas, K. (2002) Parental Responses to First and Recurrent Febrile Seizures. Acta Neurologica Scandinavica, 105, 293-299. https://doi.org/10.1034/j.1600-0404.2002.10200.x

[17] Kürügöl, N.Z., Tütüncüoglu, S. and Tekgül, H. (1995) The Family Attitudes towards Febrile Convulsions. The Indian Journal of Pediatrics, 62, 69-75. https://doi.org/10.1007/BF02752187

[18] Bavedekar, S.B., Ghule, R. and Jadhav, S. (2008) Healthcare-Seeking Behavior after Children in Children. Indian Journal of Medical Sciences, 62, 331-335.

[19] Parmar, R.C., Sahu, D.R. and Bavdekar, S.B. (2001) Knowledge, Attitude and Pratices of Parents of Children with Febrile Convulsion. Journal of Postgraduate Medicine, 47, 19-23.

[20] Adoukonou, T., Tognon-Tchègnonsi, F., Gnonlonfoun, D., Djidonou, A., Sego-Sounon, D., Gandaho, P. and Houinato, D. (2015) Social-Cultural Aspects of Epilepsy in a Rural Community in Northern Benin in 2011. Bulletin de la Société de pathologie exotique, 108, 133-138. https://doi.org/10.1007/s13149-015-0425-6

[21] Bamgbose, S.O., Elegbè, R.A. and Oyebola, D.D. (1976) Some Pharmacological Effects of Cow's Urine Concoction in Experimental Animals. West African Journal of Pharmacology and Drug Research, 3, 72-73.

[22] Huang, M.C., Liu, C.C., Chi, Y.C., Thomas, K. and Huang, C.C. (2002) Effects of Educational Intervention on Parenting Practices for Recurrent Febrile Convulsions in Taiwan. Epilepsia, 43, 81-86. https://doi.org/10.1046/j.1528-1157.2002.35501.x 